\title{
A study on relationship between cash opportunity cost and financial flexibility
}

\author{
Hassan Ghodrati, Syed Ali Lajevardi and Abbas Gaeini*
}

Department of Management and Accounting, Kashan Branch, Islamic Azad University, Kashan, Iran

\begin{tabular}{l}
\hline C H R O N I C L E \\
\hline Article history: \\
Received January 4, 2014 \\
Accepted 1 June 2014 \\
Available online \\
June 92014 \\
\hline Keywords: \\
Opportunity cost of holding cash \\
Bank performance \\
Efficiency investments \\
Financial flexibility \\
BSI
\end{tabular}

A B S T R A C T

\begin{abstract}
This study evaluated the relationship between cost and performance yield investment opportunities, cash and financial flexibility bank pays. For this study, a sample of 94 companies from companies that are part of corporate clients BSI was selected using random sampling technique. In addition, to measure the performance, three measures of economic value added, return on assets and return on equity were used. The study evaluated the relationship between cash and the opportunity cost efficiency as well as financial flexibility to invest in BSI over the period 2007-2012. Statistical methods used in this study were panel data regression. Four hypotheses were proposed to achieve the goals and the results showed that the opportunity cost of holding cash investments with financial flexibility and efficiency were inversely associated with financial performance.
\end{abstract}

\section{Introduction}

In this study, we evaluate the relationship between efficiency of cash opportunity cost and flexibility of investment funds in one of Iranian banks named Bank Saderat (BS). The primary objective of this research is to investigate whether the return on investments and financial flexibility will increase or decrease with a rise or fall in the efficiency of cash opportunity cost. Return on investments, the opportunity cost of cash and financial flexibility are considered as the external and internal dimensions. Of the external dimension, return on investments, the opportunity cost of cash and financial flexibility are normally implement to measure the performance of this bank. Of the internal dimension, return on investments, the opportunity cost of cash and financial flexibility are pivotal to decisions on investment and the investment priorities, optimal capital structure and performance evaluation of BS. Financial flexibility depends on the firm's ability in creating advantage of unexpected opportunities in terms of fiscal policy and financial structure of firms. Flexibility is the key mechanism for controlling the dynamics of investments, which happen due to the lack of flexibility and uncertainty about their financial decision. Greater financial flexibility can be defined as the ability of firms to re-allocate the cash flow between debt and equity over time to better match operational risk having a long-term value. Therefore, if the financial flexibility among firms that are

*Corresponding author.

E-mail addresses: m.p.old.king@gmail.com (A. Gaeini) 
as the bank customers is increased, it can be expected to improve their performance rendering the profitability of BS. Most firms with financial flexibility maintain a reserve borrowing power so that they can invest more in the later years of conservatism. The highest importance and necessity of this research has been the relationship between the opportunity cost of cash and performance with the investment yields and financial flexibility among the corporate clients of BS.

\section{Literature review}

In an empirical investigation, the effects of uncertainty in cash flow and payout policy during 20051994 in a sample of 5000 firms from seven countries were examined. Chua (2012) studied the effects of factors influencing the dividend policy including the cash uncertainty, conflict of interest resulting from the representation, the combination of capital and growth opportunities and concluded that there was a significant negative correlation between uncertainty in cash flow and dividend policy. Lee (2009) presented a framework linking corporate governance, cash and company evaluation with each other. The main argument was that managers of firms with weak governance are keeping too much cash leading to increased agency costs and, ultimately, decreased firm value. In addition, it was reasoned that firms with a strong local ownership structure such as a potent board of directors would probably have less agency problems to benefit from the firm's cash (Lee \& Lee, 2009)

Similarly, Sabramanian et al. (2011) investigated the relationship between the company and the amount of cash held. According to their survey, owned companies were more decentralized and diverse holding significantly less cash compared with firms that had concentrated ownership. Their further investigations suggested because firms that had a variety of properties were more connected with other firms and specific industries, had more growth and investment opportunities, hence they hold less cash.

Chua (2012) reported that financial flexibility was one of the most important determinants of capital structure. Evidence on the internal flexibility indicated that significant effects existed between cash holdings and debt capacity, and that companies needed to reduce liquidity when debt capacity increased. Arslan et al. (2012) studied the investment performance during the recession due to the flexibility of companies. They reported that financial flexibility was a key factor in absorbing investment during a recession. In addition, evidence obtained indicated that financial leverage ratio was an important component of financial flexibility. In addition, their results indicated that firms with less financial flexibility were more vulnerable in times of unusually low cash flow. Clark (2010) investigated the effect of financial flexibility on capital structure decisions. He used the final value of the cash flows as a measure for the value of flexibility. He reported that firms with bigger flexibility tend to store the value of their debt capacity for future years.

Mighati (2013) studied of the relationship between financial flexibility and capital structure decisions. The objective of his study was to make an assessment on the value of cash for investors and to study the relationship between financial flexibility and capital structure as well as the influence of financial flexibility on capital structure decisions. He reported a significant inverse relationship between debt ratio and financial flexibility and the final value of cash had the biggest effect on capital structure decisions.

Haghiqat and Bashir (2012) examined the effect of financial flexibility on the capital structure of listed companies in Tehran Stock Exchange. In this research, financial flexibility was defined through its life cycle including birth, growth and maturity. Multiple regression method was used to analyze the data. The results showed that birth-phase companies take the risk of releasing capital and low debt level and maintain modest leverage ratios. In the growth stage, firmed used financing debt and maintained high leverage ratios. Mature firms depended on internal financing and maintained lower leverage ratios. The findings of this research did not match with birth-phase companies in the field of preference theory. Sharbati (2013) in his master's thesis investigated the accruals quality on the cash 
held by the firms in the automotive and food industries listed in Tehran Stock Exchange. The findings suggested that accruals quality had a significant correlation with the amount of cash, so that the bigger the accruals quality, the less cash maintained by the company. The secondary hypothesis also confirmed that each of the factors influencing the quality of accruals was significantly associated with the level of cash holdings by companies based on Dychav Dychoo model.

Asadi (2011) surveyed the impacts of over-investment on the reaction of investors in relation to cash held and the relationship between investment and the final value of cash. The ultimate value of funds was measured through market reaction to changes in cash. The results showed that there was an inverse relationship over-investment and the value of cash. In fact, positive changes in cash could be evaluated with a discount by the investors in the over-investment firms. Furthermore, the final value of cash in over-investment companies had a significant difference compared with those without overinvestment; the ultimate value of cash was lower in the former than that of the latter. Qaemi and Alavi (2012) and Ghaemi (2013) studied the relationship between information resolution of accounting with cash balance and stated that cash balance was an important asset for firms. Harati (2011) studied the higher effect of cash on the stock returns in Tehran Stock Exchange. He reported that there was a relationship between excess cash, profitability, and growth opportunities.

\section{Research hypotheses}

\subsection{The main hypothesis}

There is a significant relationship between the opportunity cost of cash and performance with financial flexibility and return on investment in Bank Saderat Iran (BSI).

\subsubsection{Sub-hypotheses}

1. There is a significant relationship between the opportunity cost of cash with return on investments among BSI clients.

2. There is a significant relationship between performance and return on investment among BSI clients.

3. There is a significant relationship between the opportunity costs of cash with financial flexibility among BSI's clients.

4. There is a significant relationship between the performances with financial flexibility among BSI's clients.

\section{Research method}

This research aimed at assessing the relationship between cash opportunity cost and performance with return on investments and financial flexibility of BSI. Therefore, this was an applied research designed as the investigation of post events, and the type of inference procedure of the research was descriptive-inductive. This means that the descriptive method described the samples, and then statistical analyzes was applied to generalize the results of the samples to the society. This research investigated the information from the opportunity cost of funds and performance as well as the past information relating to the calculation of return on investments and financial flexibility in BSI, making this study a "post events" one. The sample size is calculated as follows,

$$
n=\frac{N \times z_{\alpha / 2}^{2} \times p \times q}{\varepsilon^{2} \times(N-1)+z_{\alpha / 2}^{2} \times p \times q},
$$


where $N$ is the population size, $p=1-q$ represents the yes/no categories, $z_{\alpha / 2}$ is CDF of normal distribution and finally $\varepsilon$ is the error term. Since we have $p=0.5, z_{\alpha / 2}=1.96$ and $N=421$, the number of sample size is calculated as $n=94$. The analysis used is descriptive and/or statistical where applicable.

1. Descriptive methods: In this paper, we described the samples using descriptive indices of the data including three groups of core indices (e.g. mean and median), scattering parameters (e.g. variance and standard deviation) and the distribution parameters (e.g. skewness and elongation indices).

2. Analyses of default hypotheses: The Kolmogorov-Smirnov (KS) was used to assess the normality of dependent and independent variables. In this test, the variables are normally distributed when the significance of variables is greater than $5 \%$. The statistic of Dowrbin- Watson was applied to assess self-correlation between variables. If this statistic is between 1.5 to 2.5 , the hypothesized variables are not self-correlated.

The Hausman and Lymer tests were employed to examine the effects of model stability and/or variability using panel data and the regression type. To test the observations with a significance level of $>0.05$, or in other words, those for which the statistical test is less than the base table, a combination of the methods is used. To test the observations with a test possibility of $<0.05$, the panel method is used to estimate the model. The panel method can be done using two models of "random effects" and "fixed effects". The Hausman's test was used to determine which model to be applied. Observations with a test possibility of $<0.05$ are tested by the fixed effects model, and for those with a test possibility of $>0.05$, the random effects model is used to estimate the model. Validation of linear relationships between the variables was determined based on the coefficient of determination and it was judged based on this factor. When this coefficient approximates to 1, it means a strong relationship and, contrarily, its proximity to zero indicates a weak estimated linear relationship.

3) Determination of relationships between variables: Based on the evaluation of default hypotheses, linear regression was used to determine the relationships between variables as expressed in the research model.

4) Generalization of the results: To generalize the relationships between variables to the entire target population, test of significant parameters were employed estimated by student t-test and Fisher's criteria.

\section{C) Research model}

In general, this model has been defined in terms of two general mathematical relationships:

$Y_{1}=f\left(x_{1}, x_{2}, x_{3}, x_{4}\right) ; Y_{2}=f\left(x_{1}, x_{2}, x_{3}, x_{4}\right)$, where:

$\mathrm{Y}_{1}=I_{i t}, \mathrm{Y}_{2}=$ Financial LEVER $R_{i t}, x_{1}=$ PSPRAD $, x_{2}=M T B_{i t}, x_{3}=M T B_{i t-1}$, and $x_{4=}$ Performance f $_{i t}$.

$I_{i t}=$ Yields of Bank Investments (the Bank's investment returns, which are disclosed when the cash flows)

Financial $L E V E R=$ Financial flexibility, PSPRAD $=$ opportunity cost of holding cash, MTB $=$ the bank's growth opportunities calculated as market value of BSI assets divided by the book value of BSI assets. Performance $=$ Bank performance index measured using three indicators of return on assets, return on equity, and added economic value.

Mathematical relationships between the variables are defined as combined linear regression equation corresponding to each of the four main research hypothesis as follows:

$I_{i t}=\alpha+\beta_{1} P S P R A D_{i t}+\beta_{2} M T B_{i t}+\beta_{3} M T B_{i t-1}+\varepsilon_{i t}$

$I_{i t}=\alpha+\beta_{1}$ Performance $_{i t}+\beta_{2} M T B_{i t}+\beta_{3} M T B_{i t-1}+\varepsilon_{i t}$

Financial LEVER $i t=\alpha+\beta_{1}$ PSPRAD ${ }_{i t}+\beta_{2} M T B_{i t}+\beta_{3} M T B_{i t-1}+\varepsilon_{i t}$

Financial LEVER $R_{i t}=\alpha+\beta_{1}$ Performance ${ }_{i t}+\beta_{2} M T B_{i t}+\beta_{3} M T B_{i t-1}+\varepsilon_{i t}$ 
Relationships between the variables were obtained using combined linear regression estimation with respect to financial information from financial statements of the Bank's corporate clients for the period 2007 to 2012.

\section{Research findings}

First, the findings were described based on the statistical processing of the data. Then, the assumptions of combined linear regression were evaluated. Based on the default hypotheses, relationships between the variables in the combined linear regression equation were estimated. Finally, the generalizations of relationships between the variables were interpreted using the significance of the estimated coefficients. In this study, data were processed by EVIEWS software.

\subsection{Description of the samples:}

The results are described in terms of statistical parameters of the variables as summarized in Table 1:

\section{Table 1}

\section{The Results of Descriptions Calculation}

\begin{tabular}{lllllllll}
\hline Variable & I & PSPRAD & MTB & MTB.1 & EVA & ROE & ROA & F .LEVER \\
\hline Number & 564 & 564 & 564 & 564 & 564 & 564 & 564 & 564 \\
Mean & $1.36 \mathrm{E}+04$ & 5.680908 & 0.69599 & 0.717141 & $1.71 \mathrm{E}+05$ & 0.005175 & 0.119674 & 0.645596 \\
Medium & 1045 & 0.140296 & 0.472082 & 0.514089 & $2.76 \mathrm{E}+04$ & 0.00258 & 0.089847 & 0.65086 \\
Mode & 0 & -0.0776 & $.0275 \mathrm{a}$ & $.0275 \mathrm{a}$ & $59393.2853 \mathrm{a}$ & $-.3156 \mathrm{a}$ & $-.3097 \mathrm{a}$ & $.2147 \mathrm{a}$ \\
Standard Deviation & $6.20 \mathrm{E}+04$ & 66.702542 & 0.8558875 & 0.7108827 & $7.14 \mathrm{E}+05$ & 0.0163186 & 0.1681001 & 0.1746709 \\
Variance & $3.85 \mathrm{E}+09$ & 4449.229 & 0.733 & 0.505 & $5.10 \mathrm{E}+11$ & 0.0001 & 0.028 & 0.031 \\
Skewedness & 8.053 & 12.481 & 8.442 & 3.366 & 10.51 & -12.598 & 7.51 & 0.217 \\
Kurtosis & 74.49 & 157.14 & 120.615 & 18.534 & 152.515 & 262.497 & 96.735 & 1.392 \\
Minimum & 0 & -0.4768 & 0.0275 & 0.0275 & $-1.44 \mathrm{E}+06$ & -0.3156 & -0.3097 & 0.1803 \\
Maximum & 794281 & 881.1529 & 14.488 & 6.9291 & $1.23 \mathrm{E}+07$ & 0.0902 & 2.573 & 1.5251 \\
\hline Sum & $7.84 \mathrm{E}+06$ & 3266.5219 & 400.1943 & 412.3562 & $9.85 \mathrm{E}+07$ & 2.9756 & 68.8125 & 371.218 \\
\hline
\end{tabular}

First row in this table represents the number of all data (564 number-year) for all variables studied. The second row shows, by separation, the collected variables; for example, return on equity is 0.0163 . The $6^{\text {th }}$ row presents the variance and dispersion of the variables around the mean such that the variance of equity returns is 0.0001 . The $7^{\text {th }}$ and $8^{\text {th }}$ rows display values of skewness and elongation of the data in relation to the normal bell-shaped curve. Among the research variables, the financial flexibility with a value of 0.217 has the lowest skewness to the right. The $9^{\text {th }}$ and $10^{\text {th }}$ describe the range of changes in the largest and smallest numbers. For the variable of return on equity, minimum and maximum values equal to -0.3156 and 0.0902 , respectively.

\subsection{Analysis of defaults hypotheses:}

With regard to the use of combined linear regression in estimating relationships between the variables, the default hypotheses of this method have been assessed.

Evaluating the assumption of normality of variables: For regression analysis, first the normality of the variables is studied by the KS test. In this test, the null hypothesis or statistically normal distribution is variable. All the independent and dependent variables were evaluated by this test and the results are summarized in Table 2. According to the results shown in Table 2, because the significance level (Sig.) of the variants is smaller than 0.05 , the $\mathrm{H}_{0}$ is rejected and $\mathrm{H} 1$ is accepted. In other words, other data are not normally distributed. A mathematical conversion (Log 2) was applied to normalize the variables, and the normality test was performed again. Based on the significance level of the normality re-test, the normal distribution of variables was accepted at a level of 0.05 . 
Table 2

The Summary Results of Kolmogorov Tests

\begin{tabular}{lcccc}
\hline Parameter & LEVER & EVA & ROE & ROA \\
\hline Number & 564 & 564 & 564 & 564 \\
Mean & 0.6536 & 164028.65 & 0.0059 & 0.1252 \\
St. Deviation & 0.17306 & $5.25 E+05$ & 0.01772 & 0.14748 \\
Deviations & 0.031 & 0.336 & 0.336 & 0.142 \\
Positive De. & 0.031 & 0.336 & 0.223 & 0.131 \\
Negative De. & -0.03 & -0.32 & -0.336 & -0.142 \\
Z Statistic & 0.741 & 7.98 & 7.969 & 3.372 \\
\hline Significance & 0.642 & 0 & 0 & 0 \\
\hline Parameter & I & PSPRAD & 564 & MTB \\
\hline Number & 564 & 564 & 0.8039 & 564 \\
Mean & 15958.048 & 4.2389 & 0.83294 & 0.6907 \\
St. Deviation & 64206.254 & 56.457 & 0.18 & 0.61756 \\
Deviations & 0.402 & 0.508 & 0.18 & 0.169 \\
Positive De. & 0.369 & 0.508 & -0.18 & 0.169 \\
Negative De. & -0.402 & -0.467 & 4.274 & -0.146 \\
Z Statistic & 9.544 & 12.072 & 0 & 4.009 \\
Significance & 0 & 0 & & 0 \\
\hline
\end{tabular}

2. Manayan test of the variables: Dickey Fuller test was used to evaluate Manayan variables in the regression estimation. The results of this evaluation are summarized in Table 3.

Table 3

The Summary of Results Stability Test

\begin{tabular}{llll}
\hline Type & Variable & Statistic & Sig. Level \\
\hline Dependent & LNI & 102.71086 & 0.000 \\
Dependent & Financial LEVER & 98.8937 & 0.000 \\
In-Dependents & LNPSPRAD & 163.358 & 0.000 \\
In-Dependents & LNROA & 389.53 & 0.000 \\
In-Dependents & LNROE & 192.969 & 0.000 \\
In-Dependents & LNEVA & 188.393 & 0.000 \\
Other & LNMTB & 126.666 & 0.000 \\
Other & LNMTB.1 & 99.9079 & 0.000 \\
\hline
\end{tabular}

As seen in the table, modification of the P-Value by the unit root test is less than 0.05 in all the independent and dependent variables indicating that the variables are Manayan. This means that the mean and the variance, and covariance of the variables were constant over time and between different years, respectively. As a result, these variables in the regression model do not create pseudoregression.

3) Lymer's F-test: This test was applied to choose between panel and integrated data. In Lymer's Ftest, $\mathrm{H}_{0}$ hypothesis of identical intercepts (integrated data) is contrasted by the opposite hypothesis H1, i.e. the different intercepts (panel data method). Table 4 summarizes the results of Lymer's Ftest.

\section{Table 4}

The Summary of F- Lamer Test

\begin{tabular}{llll}
\hline Model Number & Statistic & Sig. Level & Result \\
\hline Model 1 & 22.501 & 0.000 & $\mathrm{H}_{0}$ is accepted. \\
Model 2 & 24.641 & 0.000 & $\mathrm{H}_{0}$ is accepted. \\
Model 3 & 23.514 & 0.000 & $\mathrm{H}_{0}$ is accepted. \\
Model 4 & 24.412 & 0.000 & $\mathrm{H}_{0}$ is accepted. \\
\hline
\end{tabular}

As the results show, the probability of the Lymer's F-test for all models of this study is $<5 \%$, therefore, $\mathrm{H}_{0}$ (integration model) is not confirmed for any of the models. In other words, there is a group or individual effect and panel data method must be used to estimate the models. 
4) Hausman's test: Hausman's test statistic is calculated for the detection of constant and/or random differences in cross-sectional units, which has a chi-square distribution with a degree of freedom equal to the number of independent variables. The results of this test are summarized in Table 5.

\section{Table 5}

The Summary Results of Housman Test

\begin{tabular}{llll}
\hline Model Number & Statistic & Sig. Level & Result \\
\hline Model 1 & 5.854 & 0.4201 & $\mathrm{H}_{0}$ is accepted. \\
Model 2 & 4.102 & 0.3952 & $\mathrm{H}_{0}$ is accepted. \\
Model 3 & 6.102 & 0.5024 & $\mathrm{H}_{0}$ is accepted. \\
Model 4 & 3.748 & 0.4875 & $\mathrm{H}_{0}$ is accepted. \\
\hline
\end{tabular}

In this table, the significant level values for the determination of the constant effects model as opposed to the random effects model is $>5 \%$. Thus, $\mathrm{H}_{1}$ (constant effects model) is rejected indicating that there is no relationship between the regression error estimated and the independent variables. According to the results of Chow and Hausman's tests, the most suitable method for estimating the parameters and testing the hypotheses is the random effects model.

\subsection{Determination of the relationships between variables}

Considering the establishment of default hypotheses evaluated in the previous section, this section uses combined regression to estimate relationships between the variables.

1) Relationship between the opportunity cost of funds and return on investments: Results of this evaluation using the combined linear regression are summarized in Table 6 as follows:

\section{Table 6}

The Relation between Cash Opportunity Cost with Investment Return

\begin{tabular}{lllll}
\hline Variable & Parameter & St. Deviation & T- Statistic & Sig. Level \\
\hline LNPSPRAD & -0.358485 & 0.037225 & -9.630235 & 0.0000 \\
LNMTB & 0.751856 & 0.025177 & 29.86327 & 0.0000 \\
LNMTB_1 & -1.031423 & 0.029552 & -34.90226 & 0.0000 \\
C & 16.09875 & 0.068805 & 233.9775 & 0.0000 \\
R-Squared & 0.731993 & Alcaic Criterion & & 2.131554 \\
Adjusted R- Squared & 0.730557 & Schwartz & & 2.162299 \\
F- Statistic & 509.8314 & Henan Colic & & 2.143556 \\
Sig. Level & 0.000 & Watson Criterion & & 2.467308 \\
\hline
\end{tabular}

The estimated results show that the probability of t-test for the independent and adjusted variables is $<5 \%$. Therefore, the estimated coefficient of the variables is statistically significant. This means that these variables are important factors in determining the measure of the opportunity cost of holding cash. A significant negative correlation between returns of investments indicates an inverse relationship between this variable with the opportunity cost of holding cash, hence, the first hypothesis is confirmed by the presence of moderator variables with a confidence level of $95 \%$, i.e. $t$ there is a relationship between the opportunity cost of cash and return on investments. The coefficient of determination indicates the explanatory power of the independent variables, which can explain changes of the dependent variable up to $73.19 \%$. The F probability indicates that the entire model is statistically significant (the probability of $\mathrm{F}$ is $<5 \%$ ). Since the Dowrbin-Watson value ranges between 1.5 and 2.5, there is no self-correlation in the model. The estimated model is defined as follows:

$I_{i t}=16.09875-0.358485 * P S P R A D_{i t}+0.751856 * M T B_{i t}-1.031423 * M T B_{i t-1}$

Accordingly, there is a relationship between the yield and return on investment among the clients of BSI. 
2) The relationship between yield and return on investments: The relationship between performance and return on investments for the corporate customers of the target bank was evaluated based on the evaluation of default hypotheses by the combined linear regression. The results of this assessment regarding the estimation of parameters and a summary of the tests are summarized in Table 7.

\section{Table 7}

The Relation between Performance with Investment Return

\begin{tabular}{lllll}
\hline Variable & Parameter & St. Deviation & T- Statistic & Sig. Level \\
\hline LNROA & 0.039720 & $2.38 \mathrm{E}-12$ & $1.67 \mathrm{E}+10$ & 0.0000 \\
LNROE & 0.458850 & $2.33 \mathrm{E}-12$ & $1.97 \mathrm{E}+11$ & 0.0000 \\
LNEVA & 2.677034 & $5.08 \mathrm{E}-12$ & $5.27 \mathrm{E}+11$ & 0.0000 \\
LNMTB & 2.755697 & $3.79 \mathrm{E}-12$ & $7.27 \mathrm{E}+11$ & 0.0000 \\
LNMTB_1 & 0.979503 & $4.33 \mathrm{E}-12$ & $2.26 \mathrm{E}+11$ & 0.0000 \\
C & 72.85447 & $9.86 \mathrm{E}-11$ & $7.39 \mathrm{E}+11$ & 0.0000 \\
R- Squared & 0.875421 & Alcaic Criterion & & -45.65254 \\
Adjusted R- Squared & 0.834212 & Schwartz & & -45.60643 \\
F- Statistic & $2.37 \mathrm{E}+23$ & Henan Colic & & -45.63454 \\
Sig. Level & 0.000 & Watson Criterion & & 2.263042 \\
\hline
\end{tabular}

The estimated results show that the probability of t-test for the independent and adjusted variables is $<5 \%$. Therefore, the estimated coefficient of the variables is statistically significant. This means that these variables are important factors in determining the measure of the yield. A significant and positive correlation between the investment returns and the performance reflects a direct link between the two variables; hence, the second hypothesis is confirmed by the presence of moderator variables with a confidence level of $95 \%$, i.e. there is a relationship between the performance and return on investments. The coefficient of determination indicates the explanatory power of the independent variables, which can explain changes of the dependent variable up to $87.54 \%$. The $\mathrm{F}$ probability indicates that the entire model is statistically significant (the probability of $F$ is $<5 \%$ ). Since the Dowrbin-Watson value ranges between 1.5 and 2.5 , there is no self-correlation in the model. The regression model is defined as follows:

$$
\begin{gathered}
I_{i t}=72.85447+0.039720 * R O A_{i t}+0.458850 * R O E_{i t}+2.677034 * E V A_{i t}+2.755697 \\
* M T B_{i t}+0.979503 * M T B_{i t-1}
\end{gathered}
$$

3) Relationship between the opportunity cost of cash and financial flexibility: Based on the estimation of default hypotheses, the combined linear regression was employed to evaluate the relationship between the opportunity cost of cash and financial flexibility about corporate clients of the target bank. The results of parameters estimations and the corresponding tests are summarized in Table 8 .

\section{Table 8}

\begin{tabular}{|c|c|c|c|c|}
\hline Variable & Parameter & St. Deviation & T- Statistic & Sig. Level \\
\hline LNPSPRAD & -0.187236 & 0.003253 & -57.55202 & 0.0000 \\
\hline LNMTB & 0.033462 & 0.002200 & 15.20751 & 0.0000 \\
\hline LNMTB_1 & -0.185588 & 0.002583 & -71.85753 & 0.0000 \\
\hline $\mathrm{C}$ & 0.135114 & 0.006013 & 22.46927 & 0.0000 \\
\hline R- Squared & 0.843284 & Alcaic Criteri & & -2.743048 \\
\hline Adjusted R- Squared & 0.842980 & Schwartz & & -2.712303 \\
\hline F- Statistic & 3104.603 & Henan Colic & & -2.731046 \\
\hline Sig. Level & 0.000 & Watson Crite & & 2.420115 \\
\hline
\end{tabular}

The Relation between Financial Flexibility with ash Opportunity Cost

The estimated results show that the probability of t-test for the independent and adjusted variables is $<5 \%$. Therefore, the estimated coefficient of the variables is statistically significant. This means that these variables are important factors in determining the measure of the opportunity cost of cash. A significant and negative correlation between the financial flexibility and the opportunity cost of cash reflects an inverse link between the two variables; hence, the third hypothesis is confirmed by the 
presence of moderator variables with a confidence level of $95 \%$, i.e. there is a relationship between the opportunity cost of cash and the financial flexibility. The coefficient of determination indicates the explanatory power of the independent variables, which can explain changes of the dependent variable up to $84.32 \%$. The $\mathrm{F}$ probability indicates that the entire model is statistically significant (the probability of $\mathrm{F}$ is $<5 \%$ ). Since the Dowrbin-Watson value ranges between 1.5 and 2.5, there is no self-correlation in the model. The regression model is defined as follows:

Financial LEVER

$$
=0.135114-0.187236 * \operatorname{PSPRAD}_{i t}+0.033462 * M_{i t}-0.185588 * M T B_{i t-1}
$$

4) Relationship between the yield and financial flexibility: Based on the estimation of default hypotheses, the combined linear regression was employed to evaluate the relationship between the opportunity cost of cash and financial flexibility about corporate clients of the target bank. The results of parameters estimations and the corresponding tests are summarized in Table 9.

\section{Table 9}

The Relation between Financial Flexibility with Performance

\begin{tabular}{|c|c|c|c|c|}
\hline Variable & Parameter & St. Deviation & T-Statistic & Sig. Level \\
\hline LNROA & 0.027414 & $1.36 \mathrm{E}-13$ & $2.01 \mathrm{E}+11$ & 0.0000 \\
\hline LNROE & 0.153708 & $1.34 \mathrm{E}-13$ & $1.15 \mathrm{E}+12$ & 0.0000 \\
\hline LNEVA & 0.207829 & $2.91 \mathrm{E}-13$ & $7.15 \mathrm{E}+11$ & 0.0000 \\
\hline LNMTB & -0.117990 & $2.17 \mathrm{E}-13$ & $-5.44 \mathrm{E}+11$ & 0.0000 \\
\hline LNMTB_1 & -0.178227 & $2.48 \mathrm{E}-13$ & $-7.20 \mathrm{E}+11$ & 0.0000 \\
\hline $\mathrm{C}-$ & -2.358611 & $5.64 \mathrm{E}-12$ & $-4.18 \mathrm{E}+11$ & 0.0000 \\
\hline R-Squared & 0.784512 & Alcaic Criterion & & -51.37434 \\
\hline Adjusted R- Squared & 0.748512 & Schwartz & & -51.32823 \\
\hline F- Statistic & $2.61 E+24$ & Henan Colic & & -51.35634 \\
\hline Sig. Level & 0.000 & Watson Criterion & & 2.297552 \\
\hline
\end{tabular}

The estimated results show that the probability of t-test for the independent and adjusted variables is $<5 \%$. Therefore, the estimated coefficient of the variables is statistically significant. This means that these variables are important factors in determining the measure of the yield. A significant and positive correlation between the financial flexibility and the yield reflects a direct link between the two variables; hence, the fourth hypothesis is confirmed by the presence of moderator variables with a confidence level of $95 \%$, i.e. there is a relationship between the yield and the financial flexibility. The coefficient of determination indicates the explanatory power of the independent variables, which can explain changes of the dependent variable up to $78.45 \%$. The $\mathrm{F}$ probability indicates that the entire model is statistically significant (the probability of $\mathrm{F}$ is $<5 \%$ ). Since the Dowrbin-Watson value ranges between 1.5 and 2.5, there is no self-correlation in the model. The regression model is defined as follows:

$$
\begin{aligned}
& \text { Financial LEVER } \\
& \qquad \begin{aligned}
& =-2.358611+0.027414 * R O A_{i t}+0.153708 * R O E_{i t}+0.207829 * E V A_{i t} \\
& -0.117990 * M T B_{i t}-0.178227 * M T B_{i t-1}
\end{aligned}
\end{aligned}
$$

\section{Conclusion}

In this study, analysis of default hypotheses was conducted by econometric methods through stratified random sampling of corporate clients of the Iranian Bank Saderat. According to the results of the default hypotheses using the combined linear regression and panel data, the relationships between the variables were estimated and the parameters were tested. Based on the estimates done using combined linear regression to estimate relationships between the variables and the related tests, the following results were obtained in relation to corporate customers of the bank under review: 
1. There is an inverse relationship between the opportunity cost of holding cash and return on investments among BSI clients.

2. There is a direct relationship between the yield and return on investments among BSI clients.

3. There is an inverse relationship between the opportunity cost of holding cash and financial flexibility among BSI clients.

There is a direct relationship between the yield and financial flexibility among BSI clients.

\section{References}

Arslan, O., Florackis, C., \& Ozkan, A. (2012). Financial flexibility, corporate investment and performance: Evidence from East Asian firms. Review of Quantitative Finance and Accounting, forthcoming.

Asadi, M. (2012). The impact on the response of investors to invest more cash holdings. MS Thesis, University of Arak, Iran.

Clark, B. J. (2010). The impact of financial flexibility on capital structure decisions: some empirical evidence. Available at SSRN 1499497.

Chua, S. H. (2012). Cash holdings, capital structure and financial flexibility(Doctoral dissertation, University of Nottingham).

Ghaemi, M. (2013). The relationship between information transparency of accounting and cash balance. Journal of Management Accounting, 5(12).

Hagigat, M. \& Bashir, M. (2012). Exploring the relationship between financial flexibility and capital structure. Journal of Accounting, 3(8), 49-71.

Harati, M. (2011). Effect of excess cash on the stock returns of companies listed in Tehran Stock Exchange. Journal of Financial Engineering and Portfolio Management, 3.

Lee, K. W., \& Lee, C. F. (2009). Cash holdings, corporate governance structure and firm valuation. Review of Pacific Basin Financial Markets and Policies,12(03), 475-508.

Mighan, M. (2013). Examine the relationship between financial flexibility and capital structure decisions. Journal of Accounting Research, 1, 117113.

Sharbati, M. (2014). Evaluation of the quality of accruals on cash held by firms listed in Tehran Stock Exchange for the automotive industry and the food industry. MS Thesis University of Arak.

Subramaniam, V., Tang, T. T., Yue, H., \& Zhou, X. (2011). Firm structure and corporate cash holdings. Journal of Corporate Finance, 17(3), 759-773. 